\title{
Development of a Large Bore Superconducting Magnet With Narrow Liquid Helium Channels
}

\author{
Yinming Dai, Qiuliang Wang, Housheng Wang, Shousen Song, Baozhi Zhao, Shunzhong Chen, and Yifeng Yang
}

\begin{abstract}
A large bore $\mathrm{NbTi}$ superconducting magnet is designed, manufactured and tested. The superconducting magnet has an inner diameter of $460 \mathrm{~mm}$, outer diameter of $600 \mathrm{~mm}$ and height of $540 \mathrm{~mm}$. The magnet is dry wound using rectangular and round superconducting wires with their dimensions of $1.3 \times$ $2.0 \mathrm{~mm}$ and $\varnothing 1.3 \mathrm{~mm}$ respectively. In order to improve helium cooling effect, narrow liquid helium channels are set between adjacent layers. The magnet can generate $4 \mathrm{~T}$ central magnetic field at the designed operating current of $305 \mathrm{~A}$. The magnet has been tested in a compact cryostat. Experimental results show that the superconducting magnet reached the designed magnetic performance. Details of the magnet design, fabrication and test are described in this paper.
\end{abstract}

Index Terms-Liquid helium, solenoid, superconducting magnet, superconducting magnetic energy storage.

\section{INTRODUCTION}

A $\mathrm{S}$ the key component of the superconducting magnetic energy storage (SMES), superconducting magnet can be constructed with Cable-in-Conduit (CIC) conductor, Rutherford cables and single strand superconductors, depending on the energy and power levels [1]-[5]. For commercial SMES applications such as fast response to a load voltage dip, low cost and light-weighted SMES system is expected. It is a public opinion that solenoid superconducting magnet with high current density possesses the advantage of effective superconducting material usage for the construction of SMES magnet. For micro-SMES energy level, the solenoid magnet fabricated with single strand is easily achieved the target of light-weight. Based on this consideration, we have built a laboratory test device for demonstrating the UPS-SMES applications [6]. The magnet was fabricated in the solenoid type and the former is made of Fiberglass Reinforced Plastics (FRP) material. Due to the difference of thermal contraction between the former and the magnet windings, the magnet suffers from severe degradation during successive experiments, about $15 \%$ quenching current is declined from the designed operating current.

This paper describes a new magnet which has the same dimensions with the old one. The superconducting magnet is a

Manuscript received August 21, 2008. First published June 05, 2009; current version published July 15,2009 . This work was supported in part by the National High Technology Research and Development of China Grant 2007AA03Z244.

Y. Dai, Q. Wang, H. Wang, S. Song, B. Zhao, and S. Chen are with the Institute of Electrical Engineering, Chinese Academy of Sciences, Beijing 100190, China (e-mail: ymdai@mail.iee.ac.cn).

Y. Yang is with the University of Southampton, Southampton SO 17 1BJ, UK (e-mail: y.yang@soton.ac.uk).

Digital Object Identifier 10.1109/TASC.2009.2018755 dry-wound solenoid which has a large clear bore of $460 \mathrm{~mm}$. Stabilities of dry-wound solenoid magnets have been extensively investigated by authors [7]-[12] referring to the size effect, Minimum Quench Energy (MQE), tension and bindings. Most of their work is focused on the conductor motion induced premature quench by manipulating the radial stress.

The stability of the new solenoid magnet has been improved in such aspect as winding structures, pretension and binding. Instead of the FRP former, stainless steel material is adopted as the winding support structure. To improve liquid helium cooling abilities, the superconducting solenoid is manufactured with transparent windings. Other improvements in the magnet manufacture include conductor arrangement and large winding tensions. Tests on the magnet have been performed in liquid helium bath. There is no quenching occurred before the magnet reached the designed operating current. It is expected to replace the old magnet in the compact cryostat for further UPS-SMES experiments.

Besides, the large bore superconducting solenoid can provide a $4 \mathrm{~T}$ central magnetic field. The field uniformity around the center is better than $1 \%$ within a space of $\varnothing 100 \times 100 \mathrm{~mm}$ and $3 \%$ in $\varnothing 180 \times 150 \mathrm{~mm}$. These magnet features can also provide other application options after the UPS-SMES demonstration experiments. For example, the magnet can be used for material processing such as solidification of metal-based or polymer materials under magnetic field circumstances.

\section{MAGnet Design}

One of the design targets of the superconducting magnet is to meet requirements on magnetic energy storage of $1 \mathrm{MJ}$ for UPSSMES experiments. Besides the energy specification requirement, the magnet should provide a $4 \mathrm{~T}$ magnetic field within a clear volume of $\varnothing 180 \times 150 \mathrm{~mm}$ for other material processing applications. Field uniformity requirement within this volume is better than $3 \%$.

The magnet structure is in the solenoid type. A clear bore of $460 \mathrm{~mm}$ is necessary to meet the energy storage specification requirement. Considering the fast discharging experiments during UPS-SMES experiments, the superconducting windings are designed to be transparent to liquid helium convection. The transparent winding structure is accomplished by dry winding method and narrow liquid helium channels between adjacent layers. The solenoid is wound in 22 layers with two types of $\mathrm{NbTi} / \mathrm{Cu}$ superconducting wires. Rectangular wire with a cross section of $1.3 \mathrm{~mm} \times 2.0 \mathrm{~mm}$ is used to wind the innermost two layers, round wire of $\varnothing 1.3 \mathrm{~mm}$ is used to wind the rest layers. Parameters of the solenoid magnet are listed in Table I. 
TABLE I

MAIN PARAMETERS OF SOLENOID MAGNET

\begin{tabular}{lc}
\hline \hline Conductor & $\mathrm{NbTi} / \mathrm{Cu}$ \\
Inner Diameter (mm) & 480 \\
Outer Diameter (mm) & 560 \\
Height (mm) & 500 \\
Layers & 22 \\
Turns & 7712 \\
Operating Current (A) & 305 \\
Central Magnetic Field (T) & 4 \\
Maximum Magnetic Field (T) & 4.63 \\
Inductance (H) & 21.48 \\
Magnetic Energy (kJ) & 1000 \\
\hline \hline
\end{tabular}

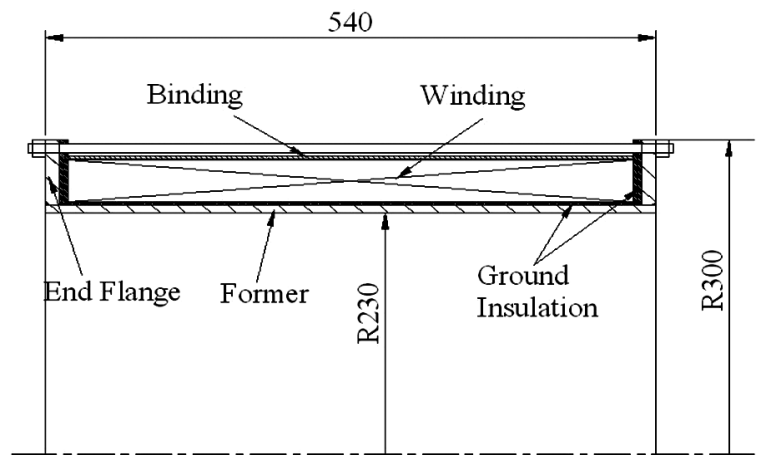

Fig. 1. Superconducting solenoid structure.

As to the magnet former, FRP material is ideal for its good insulation performance which abstain the eddy current during fast magnetic flux changing. But the big thermal contraction makes us to abandon it as the large bore former. According to our measurements on a $\varnothing 480 \mathrm{~mm}$ FRP cylinder, the diameter has been shrank $0.55 \%$ from room temperature to liquid nitrogen temperature. It is believed that the thermal contraction of the FRP former is one important factor to deteriorate the magnet performance. For this reason, 304 stainless steel is chosen as the former for magnet fabrication because of its relative low thermal contraction.

Eddy current losses of the 304 stainless steel former have been evaluated in liquid helium temperature. The heat generation during magnet discharging at $150 \mathrm{~V}$ constant voltage is about 125 joules, which will evaporate 0.04 liters liquid helium.

The magnet supporting structures consists of a $\varnothing 460 \mathrm{~mm}$ stainless steel former and two end flanges. The thickness of the former and the end flanges are $10 \mathrm{~mm}$ and $12 \mathrm{~mm}$ respectively. After ground insulation is manipulated, superconducting wires are wound directly onto it. The structure of the magnet is shown in Fig. 1.

The solenoid magnet is designed to produce a central magnetic field of $4 \mathrm{~T}$ at the operating current of $305 \mathrm{~A}$. Field uniformities around the center should meet the required $3 \%$ in a space of $\varnothing 180 \times 150 \mathrm{~mm}$. Fig. 2 shows the magnetic field distribution inside the clear bore. It shows that the field uniformity is better than $1 \%$ in a space of $\varnothing 100 \times 100 \mathrm{~mm}$ and $3 \%$ in a space of $\varnothing 180 \times 150 \mathrm{~mm}$. The maximum magnetic fields inside the solenoid windings are searched to be $4.63 \mathrm{~T}$ on the inner windings and $4.18 \mathrm{~T}$ on the outer windings.

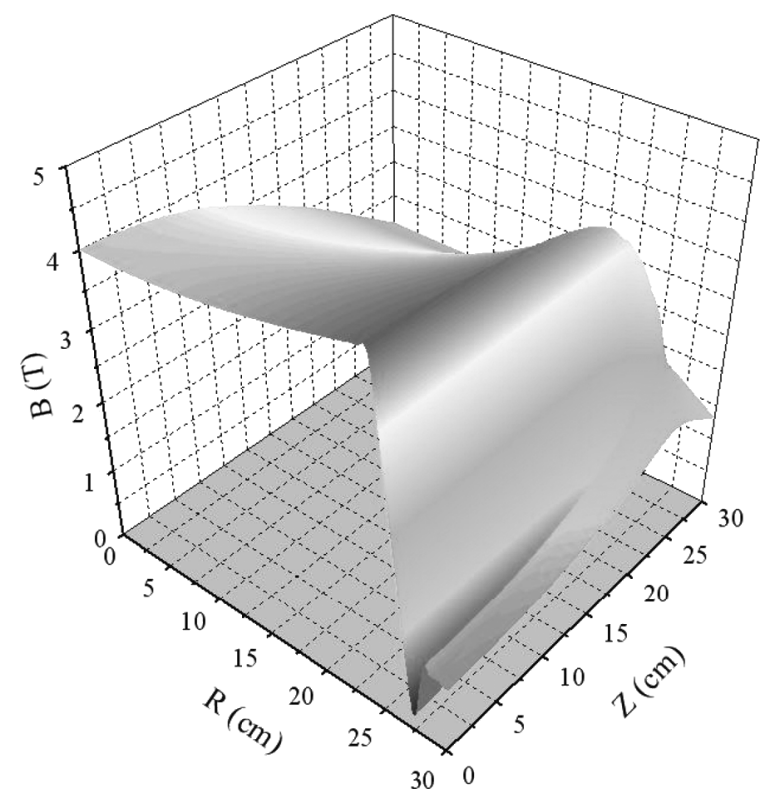

Fig. 2. Magnetic field distribution inside the clear bore.

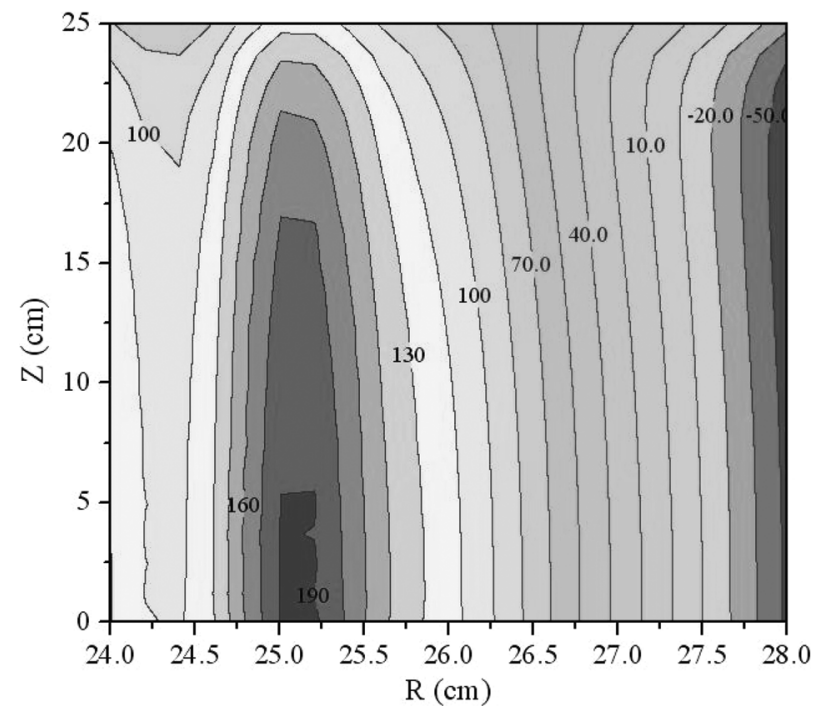

Fig. 3. Hoop stress distribution inside the solenoid windings.

Hoop stresses on the conductor are estimated based on the BJR method. Fig. 3 shows the hoop stress contour lines inside the solenoid windings. It can be seen that the maximum hoop stress is $193 \mathrm{MPa}$ which locates on the first layer of the outer winding. Hoop stresses in the inner windings are reduced to a maximum of $130 \mathrm{MPa}$ because large size rectangular conductor is used.

\section{FABrication OF the LARge Bore Solenoid MAGNET}

\section{A. Superconducting Wire}

There are two types of $\mathrm{NbTi} / \mathrm{Cu}$ wire available. One wire is a rectangular formvar-coated conductor with a cross section of $2.0 \mathrm{~mm} \times 1.3 \mathrm{~mm}$. The filaments are about 550 and the copper ratio is 2.0. Critical current at $5 \mathrm{~T}$ and $4.2 \mathrm{~K}$ is $2400 \mathrm{~A}$. The other wire is round wire with a diameter of $1.3 \mathrm{~mm}$. Its copper ratio is 1.1 and the NbTi filaments are 559. After insulation with 


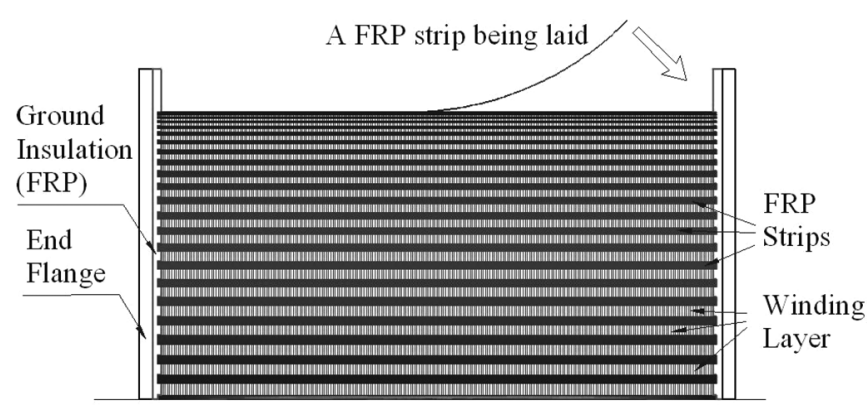

Fig. 4. Narrow liquid helium channel are formed during winding process.

polyester imine, the final diameter is $1.38 \mathrm{~mm}$. Critical current of the wire at $5 \mathrm{~T}$ and $4.2 \mathrm{~K}$ is $1925 \mathrm{~A}$. Both of the rectangular and round wires have been passed the insulation examination of $1000 \mathrm{~V}$ test before the solenoid winding is commenced.

\section{B. Solenoid Manufacture}

The magnet former is made of 304 stainless steel. Before the winding process, ground insulation is made on the former by wrapping fiber-glass tapes together with epoxy resin. After heat treatment and solidification, the insulation layer is machined to a thickness of $2 \mathrm{~mm}$. At the two ends, two FRP plates with radial grooves are also installed to the end flanges as ground insulation. The stainless steel former, the flanges and the ground insulation are drilled ventilation holes radially and axially. This will facilitate the liquid helium convection during the magnet charging and discharging.

The superconducting wires are wound onto the insulated former with a maximum tension of $80 \mathrm{~N} / \mathrm{mm}^{2}$. The rectangular wire is first used to wind the innermost two layers and the round wires are used to wind the rest layers. To encourage liquid helium ventilation freely, narrow liquid helium channels are set inside the solenoid windings. The channels are formed by laying FRP strips between two adjacent layers. The thickness of the FRP strip is $0.5 \mathrm{~mm}$ and the width is $8 \mathrm{~mm}$. Totally 90 strips are uniformly layered along each of the layer circumference. This resulted in the average channel size of $10 \times 0.5 \times 500 \mathrm{~mm}$ for liquid helium ventilation. Fig. 4 shows the process of layering the FRP strips during winding.

Because the maximum hoop stress takes place at the interface of the inner winding and the outer winding, there will be huge shear stresses during the coil winding inflation outward. The shear stress will eventually drive the round conductor to move upon the slippery FRP strip surfaces, initiating possible premature quench. To increase the resistance to the conductor motion, surfaces of the FRP strips have been abraded to increase the coarseness and then, a thin layer of epoxy glue is pasted to the FRP surfaces. Superconducting wire is directly wound onto the paste and press it to deform freely. The paste will keep semisolid state before it is heat treated to be solidified. The solenoid coil is to be heat treated in an oven at a temperature of $80^{\circ} \mathrm{C}$. The paste glue is finally solidified and a large number of serrations are formed between the FRP strip and the superconducting wire. The notches of the serration keep the conductors at its location to prevent possible conductor motion. Fig. 5 shows

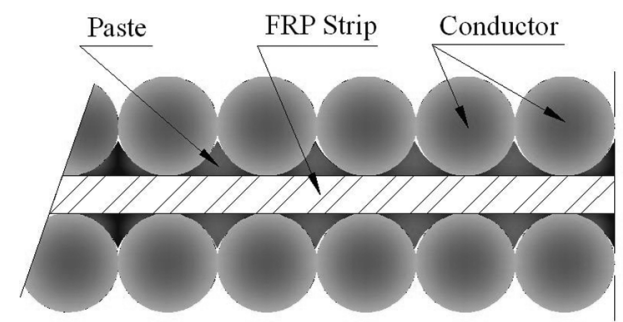

Fig. 5. Paste serration notches limit the conductor motion.

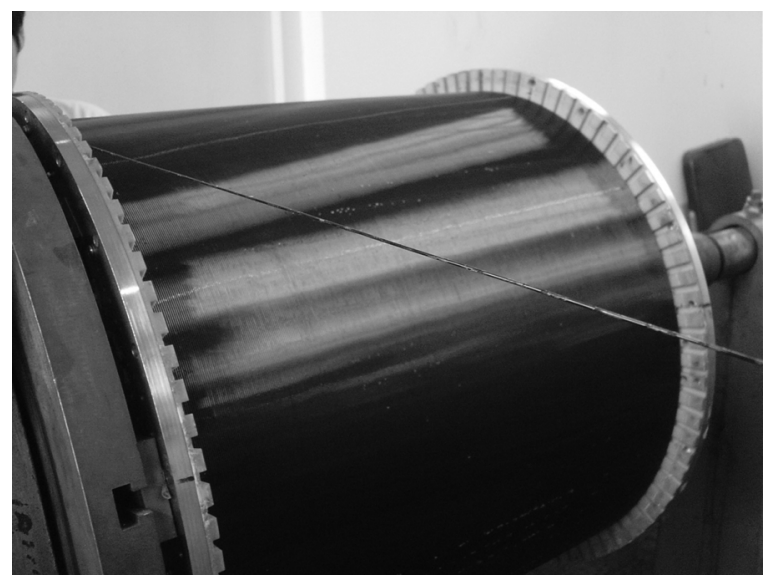

Fig. 6. Magnet winding under progress.

the solidified paste serrations to keep the conductor fixed. The solenoid magnet winding process is depicted in Fig. 6.

After the last layer winding is finished, two layers of fiber-glass tape are wrapped for ground insulation. Banding with stainless steel wire is implemented. In order to keep the solenoid windings in a firm state, banding tension of the order of $120 \mathrm{~N} / \mathrm{mm}^{2}$ is applied. Totally 4 layers of stainless steel wire are tightly wound as the banding layer.

The solenoid magnet is manufactured with $5 \mathrm{NbTi} / \mathrm{Cu}$ superconducting wires. After the superconducting joints are made, the magnet is ready for test at liquid helium temperature.

\section{Magnet Test}

Test on the magnet is performed in liquid helium bath. In order to utilize the narrow channels for effective helium convection in the case of transient disturbance, the solenoid magnet is vertically fixed to a liquid helium vessel in a compact cryostat. The cold weight of the superconducting magnet is about 250 $\mathrm{kg}$. About 500 liters liquid helium is needed to cool down the magnet to $4.2 \mathrm{~K}$. A set of warm resistor of $1.5 \mathrm{Ohm}$ is connected across the magnet terminals as the protection dumping load.

The magnet is charged with a $500 \mathrm{~A}$ superconducting power supply. The maximum output voltage is $8 \mathrm{~V}$. Current ramping rate can be changed at any time during the charging process by setting a built-in microprocessor. Besides, the ramping current is also recorded to a PC from a shunt resistor which is connected in series with the charging circuit.

Fig. 7 shows the magnet charging process. The magnet reached the designed maximum operating current of $305 \mathrm{~A}$ through stops at $100 \mathrm{~A}, 150 \mathrm{~A}, 200 \mathrm{~A}, 250 \mathrm{~A}, 280 \mathrm{~A}$ and $300 \mathrm{~A}$. No quenching is observed during the whole charging process. 


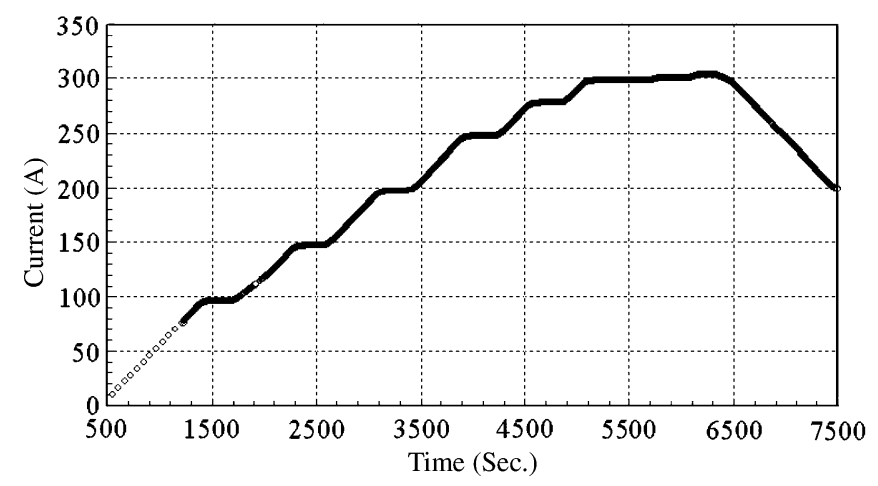

Fig. 7. Magnet charging process.

The magnet is operated at $305 \mathrm{~A}$ for about 5 minutes and then ramped down to $200 \mathrm{~A}$ at a ramping rate of $0.1 \mathrm{~A} / \mathrm{s}$. The rest energy is dumped to the protection resistor by opening the circuit breaker. At the operating current of $305 \mathrm{~A}$, the central magnetic field is $4 \mathrm{~T}$ and magnetic energy is $1 \mathrm{MJ}$.

\section{CONCLUSION}

A large bore dry wound solenoid superconducting magnet is designed, fabricated and tested. The bore size of the magnet is $460 \mathrm{~mm}$ and the length is $540 \mathrm{~mm}$. Stainless steel former with liquid helium ventilation paths is used as the magnet supporting structure. To enhance the cooling abilities, narrow liquid helium channels are set inside the solenoid windings. The FRP strips with semisolid epoxy glue paste are laid between winding layers. The notches on the FRP strip surface are effective to prevent possible conductor motion. Tests on the magnet at liquid helium bath show that the magnet achieved the designed performance without quenching. It produces a central magnetic field of $4 \mathrm{~T}$ with the field uniformity of $3 \%$ in a space of $\varnothing 180 \times$ $150 \mathrm{~mm}$. The magnet is expected to be used for UPS-SMES experiments and for other material processing applications under magnetic field environment.

\section{ACKNOWLEDGMENT}

The authors thank the K. C. Wong Education Foundation, Hong Kong for the support.

\section{REFERENCES}

[1] S. Hanai, M. Shimada, T. Tsuchihashi, T. Kurusu, M. Ono, K. Shimada, S. Koso, K. Tsutsumi, and S. Nagaya, "Design and test results of CIC conductor for a cost reduced $100 \mathrm{MW} / 500 \mathrm{kWh}$ SMES," IEEE Trans. Appl. Superconduct., vol. 13, pp. 1810-1813, Jun. 2003.

[2] S. Nagaya, N. Hirano, M. Kondo, T. Tanaka, H. Nakabayashi, K. Shikimachi, S. Hanai, J. Inagaki, S. Ioka, and S. Kawashima, "Development and performance results of 5 MVA SMES for bridging instantaneous voltage dips," IEEE Trans. Appl. Superconduct., vol. 14, pp. 699-704, Jun. 2004.

[3] T. Mito, A. Kawagoe, H. Chikaraishi, K. Okumura, R. Abe, T. Baba, K. Yamauchi, M. Yokota, T. Henmi, K. Seo, K. Hayashi, M. Iwakuma, and F. Sumiyoshi, "Development of UPS-SMES as a protection from momentary voltage drop," IEEE Trans. Appl. Superconduct., vol. 14, pp. 721-726, Jun. 2004.

[4] J. Cho, H. Kim, J. Bae, K. Sim, and K. Seong, "Fabrication and test of a 3 MJ SMES magnet," IEEE Trans. Appl. Superconduct., vol. 14, pp. 743-745, Jun. 2004.

[5] T. Mito, A. Kawagoe, H. Chikaraishi, K. Okumura, R. Abe, T. Henmi, R. Maekawa, K. Seo, T. Baba, M. Yokota, Y. Morita, H. Ogawa, K. Yamauchi, M. Iwakuma, and F. Sumiyoshi, "Prototype development of a conduction-cooled LTS pulse coil for UPS-SMES," IEEE Trans. Appl. Superconduct., vol. 15, pp. 1935-1938, Jun. 2005.

[6] Q. Wang, Y. Dai, B. Zhao, S. Song, S. Chen, Y. Bai, L. Yan, and K. Keem, "Development of a large-bore superconducting magnet with zero vapor liquid helium," IEEE Trans. Appl. Superconduct., vol. 18, pp. 787-890, Jun. 2008.

[7] M. A. Green and A. D. McInturff, "Scaling laws for modeling large superconducting solenoids," IEEE Trans. Appl. Superconduct., vol. 11, pp. 2292-2295, Mar. 2001.

[8] K. Seo and M. Morita, "Guidelines for LTS magnet design based on transient stability," Cryogenics, vol. 46, pp. 354-361, 2006.

[9] P. C. Michael, E. S. Bobrov, Y. Iwasa, and M. Arata, "Stabilization of dry-wound solenoid," IEEE Trans. Appl. Superconduct., vol. 3, pp. 316-319, Mar. 1993.

[10] M. Urata and H. Maeda, "Stabilization of superconducting dry solenoids," IEEE Trans. Magn., vol. 25, pp. 1528-1531, Mar. 1989.

[11] M. Arata, T. Hamajima, O. Ohsaki, and S. Hanawa, "Radial stress influence on high current density superconducting magnet performance with large and small bore," IEEE Trans. Magn., vol. 32, pp. 3109-3112, Jul. 1996.

[12] M. Arata, T. Hamajima, O. Ohsaki, and T. Hirumachi, "Internal stress influence on high current density superconducting magnet performance," IEEE Trans. Appl. Superconduct., vol. 5, pp. 365-368, Jun. 1995. 